\title{
Ergo
}

AN OPEN ACCESS

JOURNAL OF PHILOSOPHY

\section{What is Fake News?}

\author{
NIKIL MUKERJI \\ Ludwig-Maximilians-Universität München
}

\begin{abstract}
In this paper, I offer an analysis of fake news-a notion that has entered public debate following the 2016 US presidential election. On the view I defend, fake news is a variant of Frankfurtian bullshit, viz. bullshit asserted in the form of a news publication. Like the bullshitter, the publisher of fake news is indifferent to the truth and intends to cover up this indifference. At any rate, so I argue. To this end, I first introduce four test cases that a satisfactory analysis should match (Section 1 ), review some factors that might explain how fake news differs from related phenomena (Section 2), and develop my analysis based on that review (Section 3). After that, I clarify the individual components of the account (Section 4) and discuss possible objections to my view (Section 5) before I conclude with a few thoughts on the practical problem that fake news poses.
\end{abstract}

\begin{abstract}
$\mathrm{A}$ $\mathrm{N}$ important way in which philosophy can contribute to public discourse is by clarifying concepts that are central to it. This paper is a philosophical contribution in that spirit. It offers an account of fake news - a notion that has entered public debate following the 2016 US presidential election. On the view I defend, fake news is Frankfurtian bullshit that is asserted in the form of a news publication. According to Frankfurt's famous account, bullshit has two characteristics. There is, firstly, an "indifference to how things really are" (Frankfurt 2005: 34) on the part of the bullshitter. This does not mean that what a bullshitter says is always false. It might well be true. What it does mean, however, is that, unlike a liar, who tries to convince us that a given statement he believes to be false is true, a bullshitter simply does not care whether what he says is true. The same, I believe, is true of the publisher of fake news. Secondly, the bullshitter misrepresents "in a certain way ... what he is up to" (Frankfurt 2005: 54). Likewise, the publisher of fake news seems to misrepresent what he is up to. It appears that he wants to hide his actual motives. At any rate, so I will argue.
\end{abstract}

Contact: Nikil Mukerji nikil.mukerji <at> lmu.de 
The connection between Frankfurtian bullshit and fake news has, of course, been widely noted in the philosophical literature. However, no author has explicitly defended a conceptual analysis based on that idea. The purpose of this paper is to do just that. I believe that the analysis I offer covers all instances to which the label "fake news" is legitimately applied with the notable exception of one hypothetical case which I will discuss towards the end of the paper. To deal with this problematic case, I will suggest a distinction between two forms of fake news, viz. the bullshit type and the pure lying type. As I will explain, however, the pure lying type seems to be practically irrelevant, which is why I will propose to view fake news, for all practical purposes, as bullshit asserted in the form of a news publication.

My reasoning proceeds from the analysis of a series of cases, which I will introduce in Section 1 . The first three are intuitively not cases of fake news, while the fourth one is. A correct analysis of the concept should, accordingly, exclude the first three while including the fourth. In Section 2, I go through some factors that could explain the difference between the first three cases and the fourth. In Section 3, I propose an analysis of fake news. On this analysis, fake news is a form of Frankfurtian bullshit. As I will show, this view matches our intuitions about the four test cases. After that, in Section 4, I go into some interpretive issues to sharpen the account further. In Section 5, I consider two possible objections to my view, viz. that it is, respectively, overinclusive and overexclusive. On that basis, I conclude that a minor concession has to be made to account for the fact that there are conceivable cases of fake news that involve pure lying instead of Frankfurtian bullshit. I conclude, in the final section, with a summary of the reasoning and some suggestions for further research on the practical problem of fake news.

\section{Test Cases}

As a first step, I shall consider four cases and discuss whether, intuitively, the concept of fake news applies to them.

ACUPUNCTURE: In early 2006, the British Broadcasting Corporation (BBC) featured a three-part series on alternative medicine. In one of the episodes, a medical team in Shanghai perform open-heart surgery on a 21-year-old woman who has opted to receive acupuncture in place of a general anaesthetic. While footage of the operation is being shown, the narrator explains that the young woman's doctors have performed 300 similar operations. "What could possibly explain what's going on?", she asks. Science journalist Simon Singh asked himself the same question and set out to investigate the case. As he found, the documentary did not make any false claims. The young woman did undergo 
open-heart surgery, and she did receive acupuncture in place of an orthodox general anaesthetic. However, the documentary left out one crucial part of the story, viz. that the doctors gave their patient very powerful sedatives as well as local anaesthetics. Accordingly, Singh argued that the documentary created the false impression that acupuncture was able, by itself, to replace anaesthetics in surgical operations - a claim for which there is no evidence (Singh 2006). ${ }^{1}$

Intuitive Judgement: Intuitively, ACUPUNCTURE is not an instance of fake news. It is merely bad journalism. The documentarians, it appears, attempted to report the facts but failed to tell us all of them. Thus, they conveyed the false impression that acupuncture can be a powerful anaesthetic.

HANNITY: In May 2016, Sean Hannity of Fox News reported that Donald Trump once sent a private aircraft to help out 200 marines. These marines had come back from a military operation during the second Gulf War of 1991 and were waiting to be flown back home from Camp Lejeune in North Carolina. But their flights were delayed, and well-wishers back home had to wait for hours. Donald Trump allegedly heard about this and decided to help. So he diverted one of his aeroplanes to pick up the men. Except that he did not actually do that. According to The Fact Checker of the Washington Post, the story relied mainly on the recollection of a former marine, who reported being flown out from Camp Lejeune in a Trump jet. This part is true. However, it was not because Trump had graciously decided to help, which Hannity simply inferred. Instead, the "aircraft that ferried the troops was part of the Trump Shuttle fleet, at a time when Trump barely had control over the airline and was frantically trying to negotiate deals with bankers to prevent the collapse of his business empire" (Kessler 2016).

Intuitive Judgement: HANNITY also seems to be an instance of bad journalism or, more specifically, biased journalism. Hannity is known for his favourable attitude towards Trump. It presumably led him to accept the story based on insufficient evidence.

THE ONION: In May 2015, The Onion reported that FIFA had just announced to hold yet another Soccer World Cup in the United States, which had already begun (The Onion 2015). If true, this would have been highly unusual because the FIFA World Cup is a quadrennial tournament that had already taken place the year prior in Brazil. Of course, the story was not serious. The Onion, after all, is a satire publication. It fabricated the tale in an attempt to poke fun at the FIFA organisation which, at the time, was drowning in corruption charges. In fact, it was evident that the story was a hoax. All of its parts appeared to be deliberately crafted to make it look utterly absurd.

Intuitive Judgement: THE ONION, I take it, does not strike us as fake news ei-

1. The documentary is still available at: https://youtu.be/D53UwyJWa3w (accessed July 31, 2018).

Ergo $\cdot$ vol. 5, no. $35 \cdot 2018$ 
ther. It is satire. Unlike the BBC in ACUPUNCTURE or Sean Hannity in HANNITY, the pranksters in THE ONION did not even try to get any story right. They just made it up. The sources cited were fictitious, and the details were not even based on rumours or hunches. This was obvious because the publication does not cover up the fact that the stories are fictitious.

PIZZAGATE: In early November 2016 (shortly before the 2016 US presidential election), 4chan ${ }^{2}$ users concocted an incredible conspiracy theory: Hillary Clinton and her campaign manager John Podesta were part of a child trafficking ring that was allegedly operating out of a pizzeria in Washington called Comet Ping Pong (LaCapria 2016). Users went through Hillary Clinton's emails, which had famously been leaked by Wikileaks, and found James Alefantis among Podesta's email contacts. Alefantis owned Comet Ping Pong and had previously organized an event there to support Hillary Clinton's presidential campaign. He posted a note Clinton had sent to thank him on his Instagram account. Alongside it, he also posted photos of children. 4chan users "connected the dots" and inferred that Alefantis, Clinton, and Podesta must have been conspiring in a child trafficking ring. This unbelievable tale became known as "pizzagate." Dubious websites began breaking the story. In November alone, almost a million messages using the hashtag \#pizzagate circulated on Twitter.

Intuitive Judgement: PIZZAGATE seems to be the quintessential fake news story. It does not appear to be just a case of bad journalism because those who made it up did not, plausibly, try to get the story right. ${ }^{3}$ And it does not appear to be satire. Its details, after all, seemed to be designed to shock rather than to humour. Furthermore, the fictitiousness of the story was not evident.

\section{Explaining the Difference}

What can explain the difference between these cases?

Explanation 1: Fake news can be identified by its truth value.

Perhaps, a fake news story is simply a false news story. ${ }^{4}$ Though initially plausible, this suggestion does not stand up to scrutiny. All cases we considered in Section 1 contain (or implicate) incorrect information, but only one of them strikes

2. 4chan is an imageboard website, which has become notorious as the birthplace for outrageous web content.

3. This assumption may be questioned. I will consider alternative interpretations of the case-

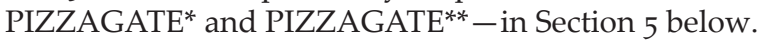

4. At least some scholars think that the falsity of the information is, in one way or another, definitional of fake news (e.g., Allcott \& Gentzkow 2017; Jaster \& Lanius in press). 
us as a fake news story. Hence, the falsity of the information does not seem to be a sufficient condition for fake news. It does not seem necessary either. When a journalist fabricates a story that happens to be true, this, too, is, intuitively, a case of fake news if it was impossible for anybody to know that the story is true. ${ }^{5}$

\section{Explanation 2: Fake news can be identified by its content.}

Maybe fake news stories can be identified in terms of their content. PIZZAGATE, unlike the other cases, contains a conspiracy theory, viz. the idea that Hillary Clinton, John Podesta, and James Alefantis conspired in running a child trafficking ring out of a Washington pizzeria. Hence, it may seem that fake news stories might be those that involve conspiracy theories. Nevertheless, it does not seem to be adequate for a simple reason: conspiracy theories can be warranted. For example, the Watergate affaire involved an actual conspiracy (Keeley 1999). Stories that covered the affaire accurately and with journalistic integrity were not fake news stories even though they reported a conspiracy theory.

\section{Explanation 3: Fake news can be identified by its source.}

Another initially plausible attempt to analyse fake news puts its source at the centre. There are, we might argue, more or less credible news sources. The Cable News Network (CNN), for example, can be considered a reliable news source, while some dubious board on the internet is not. This explanation, however, does not seem to capture what fake news is either. It is at least conceivable that reputable news outlets participate in its propagation, too. ${ }^{6}$ And it is equally conceivable that a dodgy source would publish a well-researched story that qualifies as news. So it appears the reputability of a media source is neither a necessary nor a sufficient condition for fake news.

\section{Explanation 4: Fake news can be identified by its distribution channels.}

In the recent past, fake news stories were communicated almost exclusively through the internet and, more specifically, through social media websites, such as Facebook and Twitter. However, once more, we should not misidentify this empirical link for a conceptual connection. It is entirely conceivable that

5. I discuss this kind of case in more detail in Section 5, where I address some objections to my account.

6. In fact, CNN arguably came at least quite close when they interviewed an alleged eyewitness of the Munich Shooting of 2016. While police investigations of the incident were still in progress, they brought on a young woman who reported that the gunman yelled "Allahu Akbar" before he attacked his victims (Shoichet, Ellis, \& Hanna 2016). This turned out to be a fabrication. 
fake news would be spread using more traditional means of mass communication, such as radio or newspaper. To mention only two examples, the Nazis disseminated their fake news through the radio (the so-called "Volksempfänger"), and in 1782, Benjamin Franklin famously produced an entire fake issue of a newspaper-the Boston Independent Chronicle-in an attempt to sway peace negotiations with Britain (Mulford 2008). Furthermore, genuine news is disseminated through social media as well. Many newspapers and media companies have social media channels and use them to promote their stories.

\section{Explanation 5: Fake news can be identified by the way in which it is presented.}

On the fifth explanation, fake news stories are those that are carefully crafted to optimize for user engagement and to increase the likelihood that the stories will get clicked on, liked, and shared. This strategy is often pejoratively referred to as "clickbait," which essentially means that the stories' headlines and preview photos give just enough information to raise the user's attention but not enough to satisfy their curiosity, thus maximizing the likelihood that users will click on them. However, though the clickbait strategy is indeed a typical feature of modern fake news stories, this characteristic is not unique to them and, hence, cannot be a sufficient condition for fake news. Due to economic demands, legitimate news outlets also depend on user engagement and thus resort to sensationalist presentations of their content to clickbait potential readers. Furthermore, the clickbait strategy appears not to be necessary since a fake news story that does not use clickbait seems not to be a contradiction in terms.

\section{Explanation 6: Fake news can be identified by the intent of the publisher.}

On the sixth explanation, the difference between a real news story and a fake news story is the intent that lies behind its publication. Arguably, legitimate journalists and media companies follow an ethos of truth-telling (Jacquette 2010). Though they do need to make money, sell advertisements, and break stories that excite their readers, they also aim to get the story right. In contrast, "fake news is completely made up and designed to deceive readers to maximize traffic and profit" (Hunt 2016), as Elle Hunt of The Guardian explains. Those who publish fake news are, it seems, indifferent to the truth. To be sure, this does not mean that they always make false claims. If it suits their purpose, publishers of fake news will, on occasion, deliberately sprinkle some truths on top of their stories, for example, to make them more credible. 7 However, their knowledge that a

7. The pizzagate story, e.g., contained many correct details. The restaurant Comet Ping Pong was real. So were the characters of the story. Furthermore, there was indeed a connection between Alefantis, Podesta, and Clinton. 
given story is false (or lack of knowledge that it is true) will not keep them from publishing it if they believe that doing this helps them, for example, to make money. Also, it appears that publishers of fake news seek to deceive us about their intent. Hence, it may be reasonable to regard fake news as being essentially characterized by two features: those who publish it are, it seems, indifferent to the truth, and they try to avoid letting us know this. ${ }^{8}$

These two features are, of course, the hallmark of Frankfurtian bullshit. As I have explained in the introduction, according to Frankfurt, bullshit is characterized, firstly, by an "indifference to how things really are" (2005: 34). This is not to say that what a bullshitter says is always false. It might well be true. Unlike a liar, however, who seeks to convince us that a given statement he believes to be false is true, a bullshitter does not care about whether his utterances are true. The same, it appears, applies to the publisher of fake news. Secondly, the bullshitter misrepresents "in a certain way ... what he is up to" (Frankfurt 2005: 54). In like manner, the publisher of fake news misrepresents, it seems, what he is up to. It appears that he wants to hide his actual motives.

\section{An Analysis of Fake News}

It seems reasonable to suggest, then, that fake news is simply a species of Frankfurtian bullshit, as the following analysis holds. ${ }^{9}$

Analysis

Fake news is bullshit asserted in the form of a news publication.

This analysis contains three conditions that, given what I have said so far, seem to be necessary and jointly sufficient for the concept of fake news to apply.

8. At least some of the publishers of fake news explicitly acknowledge their indifference to the truth, as BBC journalist Emma Jane Kirby reports. She has interviewed a number of them in Veles - a town in Macedonia where many of the most influential fake news stories of the 2016 US presidential election originated. One of their publishers, a young man Kirby refers to as "Goran," explains how he and other fake news producers feel about the US election. He responds that "Teenagers in our city don't care how Americans vote. ... They are only satisfied that they make money and can buy expensive clothes and drinks!" (Kirby 2016).

9. The idea that fake news might be a species of bullshit was, to my knowledge, first proposed by Pennycock and Rand (2017). However, these authors acknowledge that there are different types of bullshit and concede that they do not know to which kind of bullshit fake news belongs. Neither do they argue for their conjecture. The connection between bullshit and fake news is also noted by Dentith (2017), Goodin and Spiekerman (2018), and Rini (2017). None of these authors, however, argue for the connection in much detail. 
These are the Bullshit Condition (B), the Assertion Condition (A), and the Publication Condition (P). According to $\mathrm{B}$, something qualifies as fake news only if it contains bullshit in the Frankfurtian sense. ${ }^{10}$ The publisher has to be indifferent to the truth $\left(\mathrm{B}_{1}\right)$ and cover up this fact (B2). ${ }^{11}$ According to A, it is necessary for fake news that the bullshit contained in it is asserted, that is, not only derivable by conversational implicature. Frankfurt, in his original essay, does not distinguish between bullshit assertions and bullshit implicatures (Webber 2013). As we will see in Section 4, this is important, however, to account for the phenomenon of bullshit journalism. Finally, according to $\mathrm{P}$, for something to be fake news it is necessary for it to be presented in the form of a news publication. That is, any bullshit uttered in private is not fake news. For a story to qualify as fake news, it has to be made available publicly, for example, in paper form, on the radio, on the internet, etc.

This analysis does at least two things that we should expect from it. Firstly, it matches our intuitions about how the four cases should be categorized. Secondly, it elucidates the difference between them. ACUPUNCTURE is not an instance of fake news because the dubious suggestion that acupuncture is a powerful anaesthetic was not explicitly asserted but only implicated. However, even if this claim had been asserted, the case would not qualify as a fake news story because, plausibly, the documentarians did at least try to get the story right. ${ }^{12}$

In contrast, Cases 2, 3, and 4 do contain explicit, problematic published assertions. So conditions A and P are fulfilled here. However, condition B seems to be fulfilled only in one of the cases. To see this, consider, first, HANNITY, which

10. The qualifier "Frankfurtian" is important here. On Frankfurt's account, whether a given utterance is a piece of bullshit depends on the state of mind of the person uttering it. Note, however, that there are different conceptions of bullshit and that some of them regard bullshit as mindindependent (Cohen 2002). In addition, Carson (2009; 2010; 2016) has pointed out that there might be a category of evasive bullshit which Frankfurt's conception fails to take into account.

11. As an anonymous reviewer for this journal has pointed out, the publisher of a story may or may not be its author. So why should we focus on the publisher's intent rather than the author's? This is a fair point. For the purpose of the present paper, I ignore this complication mainly for reasons of simplicity. That is, I assume that the publisher vouches for and controls the quality of the journalism of his or her publication. To me, this assumption is sufficient reason to focus on the publisher's intent. In certain practical situations, however, authors may be in a position to decide, unilaterally, whether a story of theirs gets published and in which form. In that case, plausibly, the author's intent should matter and not the intent of the passive publisher who is, as it were, "out of the loop." In more complicated situations where more than one person decides whether or not a story sees the light of day, we should, plausibly, focus on collective intentions, as discussed, e.g., by Schweikard and Schmid (2013).

12. In previous presentations of my argument, I have been criticized for making this charitable assumption. I should, therefore, point out that, if my interpretation of ACUPUNCTURE is incorrect and the documentarians did not actually care about the truth, then their story could, of course, be regarded as containing bullshit implicatures and, ipso facto, as bullshit journalism. I will consider this case, ACUPUNCTURE*, in Section 4. 
is, intuitively, merely an instance of biased journalism. In this case, the journalist Sean Hannity did not get the story right because he did not dig deep enough or fell for the pitfalls of his cognitive psychology (or both). Nevertheless, he plausibly aimed at the truth. This is supported, for example, by the fact that he did bring on a genuine eyewitness to back up his story. In other words, Hannity failed to exhibit condition B1. There was no indifference to the truth, no bullshit, and, hence, it seems, no fake news story. ${ }^{13}$

Consider, next, THE ONION, which is a satire story. The difference between satire and fake news does not lie in B1. The two are similar to the extent that both the satirist and the publisher of fake news do not aim to report the facts accurately. They are, I shall assume, both indifferent to the truth and up to something else. ${ }^{14}$ The satirist seeks to ridicule, mock, parody, or caricature. ${ }^{15}$ To this end, he helps himself rather liberally to stylistic devices (e.g., hyperbole and provocation). He does this as it helps him to make his point more effectively. ${ }^{16} \mathrm{But}$, of course, this is not the best way to communicate information accurately. Hence, a satirist will tend to run the risk of misinforming his audience. In that regard, what he does is akin to what the publisher of fake news does. However, there still is an essential difference between the two regarding condition B2. Satirists usually do not cover up their motives - at least not systematically. This holds in the online sphere as well, as Gillin (2017) explains. Satire websites, he says, "may or may not make it clear on individual links that their stories are fake, but will almost always say in a disclaimer somewhere on their site that their content is exaggerated or fictional." In contrast, the publisher of fake news keeps his cards

13. Of course, the case of Hannity also lacked B2, which is entailed by the lack of $B_{1}$. There cannot be an attempt to cover up that one is indifferent to the truth if one is not, in fact, indifferent to the truth. Also, the proviso I added in regards to ACUPUNCTURE (see Footnote 12) applies here as well. If, that is, Hannity was, contrary to my assumption, indifferent to the truth of the story, then HANNITY might also qualify as a fake news story.

14. This assumption may, of course, be criticized as expressing a naïve understanding of the nature of satire and of the relationship between satire and truth. The American comedian and politician Al Franken paints a different picture of that relationship. According to him, "What a satirist does is look at a situation, find the inconsistencies, hypocrisies, absurdities and cut through all the baloney and get to the truth" (quoted by Branham 2009: 139). Note, however, that the assumption that the satirist is not indifferent to the truth would lend further support to my argument because it would make for an even sharper contrast between satire and fake news. This is because, if satirists were not actually indifferent to the truth, satire would not even fulfil B1.

15. In fact, it is far from easy to tease apart the motives of online satirists. According to Gillin (2017), "They could be writing stories purely for entertainment, or they may be trolling a particular set of voters."

16. An anonymous reviewer for this journal has pointed out that, as Davis (2017) has argued, literally false statements might still be useful for conveying information about the subject matter. A satirist may, e.g., ironically comment on a politician's statement by saying: "Yes, and pigs can fly." This is a deliberately false and absurd statement. However, it is not to be believed by the recipient. Rather, it is a stylistic device that is meant to draw attention to the absurdity of the politician's utterance. 
close to his chest. As I pointed out above, he intends to fool readers into thinking that what he reports is actual news when, in fact, it may be entirely made up. Though, as I assume, the satirists in THE ONION were, like the publishers of fake news, indifferent to the truth, they were not disingenuous about that fact, while publishers of fake news are. The latter, in other words, exhibit both B1 and B2, while satirists fulfil only $B_{1}$.

Finally, consider PIZZAGATE. The pizzagate story evidently fulfils both BI and B2. Firstly, those who published the story were arguably indifferent to the truth. ${ }^{17}$ They must have known, after all, that there was not a shred of credible evidence to support the allegation that Hillary Clinton was involved in a sextrafficking ring. It was all made up. Secondly, these publishers were dishonest about that fact. Had they stated clearly that the story was merely a joke or wild speculation, many internet users would likely not have taken the bait. These two facts, it seems, are what makes pizzagate a fake news story.$^{18}$

To sum up, the analysis I have proposed at the beginning of this section does quite a bit of work. It appears, firstly, to fit the four test cases, and it can explain, secondly, the intuitive difference between them. This, I believe, is not an artefact of the chosen scenarios. Using a fact-checking website like Snopes, we can readily ascertain that the analysis correctly categorizes many further stories as fake news stories, while properly excluding others from that category. ${ }^{19}$ This, of course, does not mean that there are no possible objections to it. In Section 5, I shall discuss two criticisms that have previously been pointed out to me. Before that, however, I shall address some interpretative issues in the ensuing section.

17. This assumption may, of course, be questioned. That is why I will introduce two alternative interpretations in Section 5. In PIZZAGATE*, the publishers of the pizzagate story are assumed to be deluded enough to believe their own story. In PIZZAGATE**, we suppose that they are lying.

18. I mentioned in Footnote 16 that, as Davis (2017) has argued, literally false information can be an effective tool for expressing a genuine point. As an anonymous reviewer has pointed out, this might also apply to PIZZAGATE. In this case, it may not have been the aim of the publishers "to say anything literally true about Clinton at all but rather to express dislike for her as a candidate." I do not believe, however, that this is likely in the case of PIZZAGATE. According to Silverman (2016b), the story was first put out in the form of a news publication by Adl-Tabatabai (2016). In his text, he compiles a number of sources that seem to implicate Clinton in the pedophile scandal. It appears evident that Adl-Tabatabai did not do this merely to express an unfavourable attitude towards her as a political candidate but, rather, to make readers believe the story.

19. Snopes articles usually provide enough circumstantial evidence for us to decide whether a given story was published with an indifference to the truth (B1) and with an intention to deceive (B2). There is, e.g., clear evidence that both conditions are met in obvious examples of fake news stories like "FBI Agent Suspected in Hillary Email Leaks Found Dead in Apparent MurderSuicide" (Mikkelson 2016) and "Creepy Clowns plan Halloween Night Purge, Cops warn 'Stay Inside"' (La Capria 2017). These stories were clearly made up, and their publishers tried to deceive us about that fact (as evidenced, e.g., by the lack of a disclaimer on their website). At the same time, some stories on Snopes do not, intuitively, deserve the label "fake news," e.g. the story that Donald Trump had the bust of Martin Luther King removed from the Oval Office (Emery 2017). This was an honest reporting error, and there was, plausibly, no intention to deceive. 


\section{Clarifications}

In the previous section, I introduced my analysis of fake news and showed that it matches the four cases that I presented in Section I. In the present section, I shall address some interpretative issues that concern conditions $B$ (consisting of B1 and $\left.\mathrm{B}_{2}\right), \mathrm{A}$, and P. ${ }^{20}$

\section{Bullshit Condition $\left(B_{1}\right)$}

On $\mathrm{B}_{1}$, the publisher of a fake news story is "indifferent to the truth." Strictly speaking, this is loose talk. Indifference, after all, is a preference relation. Hence, though we often say that someone is "indifferent to something" (e.g., the truth), this turn of speech is, in fact, elliptical. ${ }^{21}$ When we meaningfully employ the concept of indifference, we say that someone is indifferent between at least two objects. So, rather than saying that someone who is truth-indifferent is indifferent to the truth, we should at least say that she is indifferent between truth and falsehood.

This way of putting it, however, is also problematic because truth and falsehood do not exist independently of truth-bearers, for example, beliefs. So we should say, it seems, that one is truth-indifferent to the extent that one has, as Quassim Cassam has recently put it, "a casual lack of concern about whether one's beliefs have any basis in reality" (Cassam in press) or not. Cassam calls this attitude "epistemic insouciance," and it is, arguably, one important form of truth-indifference.

Epistemic insouciance, however, is not exactly what is required by B1. A person who is indifferent to whether her beliefs are true or false could, after all, avoid bullshitting by never communicating them to others. ${ }^{22}$ Evidently, then, what matters here are not beliefs but communications. ${ }^{23} \mathrm{~B} 1$ requires indifference to whether one's communications are true or false. ${ }^{24}$

Now, to say that a publisher is indifferent to whether his communications

20. I am indebted to an anonymous reviewer for this journal for pointing out to me that there are some interpretative issues that needed addressing.

21. Harry Frankfurt, e.g., uses the phrase "indifference to how things really are" (Frankfurt 2005: 34).

22. Russell Hurlburt puts this insight more generally by observing that "[to] bullshit is an inter-personal act" (2011: 18).

23. Cassam, it seems, neglects this difference in his discussion of epistemic insouciance. At one point, he says that this attitude implies "an indifference to the truth or falsity of [the speaker's] utterances" (Cassam in press; emphasis added). In another passage, then, he says that epistemic insouciance consists in a "lack of concern about whether one's beliefs have any basis in reality" (Cassam in press; emphasis added).

24. Having clarified this, I suspect that the two forms of truth-indifference are closely related empirically. A person who is truth-indifferent about her beliefs and who tends to say what she 
are true or false can mean different things. To see this, imagine a publisher who is considering publishing a story. He is doubtful about its truth. In one sense, then, he is truth-indifferent if he chooses to publish the story anyway. Let us refer to this type of truth-indifference as "truth-indifference ${ }_{1}$. " Note, however, that our publisher might not be truth-indifferent in another sense. Suppose that he does consider his lack of conviction in the story's truth as a reason for not publishing it but decides that, all things considered, it would be for the best to publish it anyway. In that case, there is a sense in which the publisher is not truthindifferent-call it "truth-indifference ${ }_{2}$." He recognizes, after all, that the truth or falsehood of a story is a factor to be taken into account. Now, there is yet another sense in which our publisher can be truth-indifferent. Suppose he decides not to publish any stories he is doubtful about, and suppose, further, that he does this because he considers the truth of a story an important factor. He is, then, not truth-indifferent ${ }_{1}$ or truth-indifferent $_{2}$. He may, however, be truth-indifferent in a further sense - call it "truth-indifference, ${ }_{3}$ - if he is only concerned with the truth of a story for instrumental reasons. A political regime might impose severe penalties for false reporting such that the publisher is forced to prioritize truth. He might, however, fail to see the intrinsic value of truth and would, if there were no penalties, not hesitate to publish any story whatsoever.

Which of these three notions of truth-indifference is relevant in the context of B1? The answer is obvious: A story is fake news only if its publisher chooses to publish it despite his doubts about its truth because this is, all things considered, preferable for him to do. This is truth-indifference ${ }_{1}$. It is irrelevant whether the publisher regards truth as a pro tanto reason for his decision (truth-indifference ${ }_{2}$ ), and it is equally irrelevant whether he thinks that a story's truth matters intrinsically (truth-indifference ${ }_{3}$ ). ${ }^{25}$

To confirm this, consider PIZZAGATE again. I assumed that the publishers were truth-indifferent ${ }_{1}$. This feature is necessary because, had the publishers not been truth-indifferent ${ }_{1}$, there would not have been any fake news story to begin with since they would not have decided to publish it. Now, let us imagine that the publishers were not truth-indifferent ${ }_{2}$ and truth-indifferent ${ }_{3}$. That is, they were concerned about the fact that their story was likely false, and they also regarded truth as an intrinsically desirable feature in a story. However, they

believes will, of course, frequently end up being truth-indifferent about her communications as well. In other words, epistemic insouciance will often lead to bullshit, as Cassam, of course, notes.

25. Frankfurt (2005) briefly discusses why an antirealist outlook might produce bullshit. Indeed, if you "deny that we can have any reliable access to an objective reality" and "reject the possibility of knowing how things truly are" (Frankfurt 2005: 64), you will, it seems, adopt attitudes that are functionally equivalent to all three kinds of truth-indifference. You will dismiss the notion that you should, all things considered, publish a story only if it is true (truth-indifference ${ }_{1}$ ), that the truth of a story is a relevant consideration in deciding what to do with it (truth-indifference ${ }_{2}$ ), and that the truth of a story is an intrinsically important factor (truth-indifference ${ }_{3}$ ). 
decided to publish their story anyway because they judged that it was, all things considered, more important to fight (what they took to be) a reprehensible political candidate than to speak the truth. Adding these details evidently does not change our evaluation of the case. Even with these factors in the picture, PIZZAGATE remains, I believe, a paradigm case of fake news. To sum up, then, what is required by $\mathrm{B}_{1}$, that is, the truth-indifference condition for fake news, is that the story's publisher decides to publish it despite there being doubts about its truth.

\section{Bullshit Condition (B2)}

The verb "to deceive" is an achievement word (Ryle 1949/2009: 131ff.), unlike, for example, "to lie". I have not deceived you unless you actually come to believe something that I wanted you to believe. However, the intention to deceive does not require that effect. According to condition B2, the publisher is required to intend to deceive his audience. Whether he is successful in achieving this is immaterial.

That said, let us investigate the nature of the intention. As I have explained, a fake news publisher does not necessarily seek to deceive us about the facts. As a bullshitter, however, "What he does necessarily attempt to deceive us about is," in Frankfurt's words, "his enterprise." He "misrepresents what he is up to" (Frankfurt 2005: 54). While he is, in fact, truth-indifferent (in the sense of truthindifferent $t_{1}$ ), he tries to come across as someone who is concerned with the truth.

There are various ways to do this. One is to lie. The fake news publisher may, for example, provide false information about himself or his publication (e.g., in the "About Us" section of his website). Another method is to work with false implicatures, for example, by citing fake sources to create the impression that one pays heed to the evidence. These two examples, however, are not the only methods a publisher can use to deceive us about his intent. On the traditional definition of deception, "To deceive $=_{\mathrm{df}}$ to intentionally cause to have a false belief that is known or believed to be false" 26 (Mahon 2016). Accordingly, a fake news publisher does not even have to say anything to deceive us about his enterprise. He can, for example, misrepresent what he is up to by having a misleading web address - one that "sounds legit" - or by mimicking website addresses and designs of acknowledged news sources. ${ }^{27}$ Finally, it is not even clear that a fake

26. Note that the traditional definition of deception is associated with difficulties, as discussed by Mahon (2016). I use it, rather than more complex proposals, to sidestep issues that I take to be irrelevant to the present discussion.

27. Many examples illustrate this strategy. The hoax that George H. W. Bush had died in 2017 was, e.g., distributed through websites with names like "TV-CNN.com" and "Fox-Channel.com," which mimicked the web addresses of the well-known TV channels CNN and Fox News (Evon 2017). In addition, there have been fake news sites named "Breaking-CNN.com," "Fox-Channel. com," "NBCNews.com.co," and so on. 
news publisher needs to do anything to deceive his audience. If he purposely refrains, for example, from putting up a disclaimer on his website which states that his stories are fictitious, this, too, is, arguably, intentionally deceptive.

To sum up, B2 does not require that the publisher is successful in deceiving anyone. It does, however, require that he try. As we have seen, there are various things he can do to this end. He can lie, mislead, or refrain from accurately classifying the information provided.

\section{Assertion Condition (A)}

It may seem at first glance as though my analysis implies that any bullshit in the form of a news publication has to be classed as fake news. This consequence, a critic might argue, is unwelcome. We should, after all, allow for the category of bullshit journalism. Intuitively, at least, there should be such a category because in some cases, we would probably go so far as to call some bad and biased journalism "bullshit," without going so far as to call it "fake news."

This concern can be answered by distinguishing between bullshit assertions and bullshit implicatures (Webber 2013). When somebody asserts bullshit, they are indifferent regarding the truth of their statements. In contrast, when somebody implicates bullshit, they are indifferent to the truth of the implicatures of their statements. ${ }^{28}$ Note, however, that, on A, it is a necessary condition for fake news that the bullshit content is asserted rather than merely implicated. Thus, it makes room for the category of bullshit journalism. If journalists assert bullshit in their publications, then, I propose, they should be seen as peddling fake news. If, in contrast, they merely implicate it, they should be viewed as practising bullshit journalism.

To illustrate, consider a variation of ACUPUNCTURE from Section 1-call it ACUPUNCTURE*. In this case, let us assume, the documentarians were hellbent on avoiding false assertions but entirely indifferent about misleading their audience through conversational implicatures. They omitted important facts and did not care whether or not their story created a false impression. In this case, there is, by stipulation, still no bullshit assertion. Hence, it is still not a case of fake news. However, the documentarians were, as we assumed, indifferent to the truth of the implicatures that their audience might draw from their work. That means that there is now a bullshit implicature such that the case qualifies as an instance of bullshit journalism. Hence, as ACUPUNCTURE* illustrates,

28. There are various ways in which journalists can implicate bullshit without asserting it. They can, e.g., report only the arguments on one side of an issue while neglecting counterarguments. Due to the Gricean maxim of quantity (Grice 1989), which demands that they give all relevant information, they can thereby implicate that the issue is an open-and-shut case though it might not be. 
my analysis does, in fact, allow for cases that fall into the category of bullshit journalism without falling into the category of fake news. This is ensured by Condition A.

\section{Publication Condition (P)}

Finally, consider P. It states that a story has to be presented in the form of a news publication to qualify as fake news. What does this mean, however? One approach to clarifying this is to compile a list of possible distribution channels for news publications - for example, newspapers, news programmes (on television and radio), news websites - and to say that anybody who spreads bullshit assertions using these distribution channels spreads fake news. Social media websites make things more complicated, however, because it is not always clear when assertions on social media accounts have the form of a news publication. Some certainly do. For example, when a CNN employee posts a story on CNN's Twitter account, this story is clearly presented in the form of a news publication. In contrast, when I share something on my Twitter account (that has five and a half followers), this, certainly, does not have the form of a news publication. That said, there are evidently borderline cases. If, for example, a CNN journalist posts a story to a private social media account that has a substantial following, it is not entirely clear whether this story is presented in the form of a news publication. At any rate, this is not clear to me. Hence, there is at least some degree of vagueness in the analysis I propose. To an analytically-minded person, this may seem like a problem. I believe, however, that it is not a fair point of criticism when used against my analysis of fake news. After all, fake news is like news, except fake. Accordingly, the concept of fake news has to be at least as vague as the concept of news. This is not to say, of course, that all objections to my analysis can be dispensed with so easily. Some deserve closer attention. In the next section, I will turn to some of them.

\section{Objections}

Any conceptual analysis may fail in one of two ways. It may, firstly, be overinclusive and, secondly, overexclusive. That is, it may include cases that it should exclude and exclude cases that it should include. Accordingly, there are two types of criticism a critic may level against the analysis of fake news that I have proposed. Though I cannot address all possible instantiations of the two types of criticism, I will discuss specific forms of them that strike me as important. 
Objection 1: The analysis is overinclusive.

Consider a concrete version of Objection 1 . To this end, imagine a journalist who publishes a story that is entirely correct in all its details. However, this is not because she researched it carefully. Instead, she simply wanted to write an exciting story to generate many clicks. So she wrote it down without any concern for the truth but, by a freakish coincidence, got everything right. What she published is, then, Franfurtian bullshit asserted in the form of a news publication. However, a critic may insist that this is, intuitively, not an instance of fake news.

There are three ways to deal with this case. The first is to deny that it is not, intuitively, an instance of a fake news story. I believe that once we carefully consider the details of the scenario, it becomes clear that the story the journalist reports is fake news. After all, she did not attempt to do what constitutes genuine newsmaking. She did not do any research, interview witnesses, or consult with experts. In other words, she did nothing that bears even a remote resemblance to what a genuine newsmaker does. To that extent, her purported news story is clearly fake. The fact that it happens to be entirely accurate does not, intuitively, detract from its fakeness. ${ }^{29}$

The second way to address the objection is to accept, for argument's sake, that the idea of true fake news is genuinely counter-intuitive but to argue that the intuition in question is based on a cognitive error and should, hence, be dismissed. In the present case, there are two reasons for suspecting that this might be so. Firstly, the line between fake and genuine news is especially thin here. Accordingly, it might be easy to overlook it. After all, not much is missing from the fake news story for it to become a genuine news story. It only takes one fact-checker who looks into it with proper regard for its truth and re-publishes it. This would make the story a genuine news story. Secondly, the hesitation to categorize a true piece of information as fake news might be explained by a cognitive bias, specifically the hindsight bias. It is known that people tend to perceive an event as more predictable once it has occurred - that is, in hindsight-than before it has happened. ${ }^{30}$ As Levy (2016) explains, "This perception could mediate inferences about the likely state of mind of an agent." In the present case where a fabricated news story turns out to be true by coincidence, those who intuit that it is not an instance of fake news may misjudge the state of mind of

29. Frankfurt draws our attention to the same distinction in the context of his discussion of bullshit. "[O]ne must recognize," he says, "that a fake or a phony need not be in any respect (apart from authenticity itself) inferior to the real thing" (Frankfurt 2005: 47). In other words, a proposition which was produced with no regard for the truth may still happen to be true. In like manner, a purported news publication that was produced with no regard for the truth - a fake news publication-may also be entirely true.

30. For a thorough literature review, see Roes and Vohs (2012). 
the publisher. They may assume, contrary to the stipulations, that the publisher must have been to some degree warranted in reporting this story and that it was, hence, not fake news. To be sure, these are both armchair speculations that should be tested empirically.

The third reply is to present the analysis as a contribution to normative conceptual engineering rather than an attempt to capture intuitions descriptively. ${ }^{31}$ Viewing it through this lens might be useful should it turn out not to capture our (trustworthy) intuitions sufficiently well. An argument to that effect would have to show that the proposed analysis fulfils certain normative criteria to a higher degree than the common-sense concept. ${ }^{32}$ At this point, I cannot provide a detailed discussion of how such an argument might proceed. After all, surveying the conceptual engineering literature would take us too far afield, and systematic empirical research into the common-sense concept of fake news seems to be practically non-existent. Accordingly, we cannot compare the properties of the two concepts in any detail. However, I suspect that my analysis would do rather well in comparison to what the common-sense concept turns out to be. This is because it has some desirable features, as we can ascertain, for example, by applying Rudolf Carnap's criteria for the adequate explication of a concept (Carnap 1950/1962). According to these criteria, there should, firstly, be a sufficient similarity between the explicandum (i.e., the common-sense concept) and the proposed explicatum (i.e., the engineered concept) such that "most of what previously was said with the former can now be said with the help of the latter" (Carnap 1950/1962: 6). As far as I can see, this is evidently the case since the analysis captures, as we have seen, most, if not all, of the intuitions that common-sense provides. It should, secondly, be sufficiently exact. This seems to be the case as well. At any rate, the analysis is exact to the extent that the notions of bullshit, assertion, and news publication are exact. The first two are established concepts in philosophical discourse, and the third, though it may involve some degree of indeterminacy, is an everyday concept that does not appear to be especially problematic. Thirdly, the explication should be fruitful. To Carnap, this meant that the explicatum should be "useful for the formulation of many universal statements (empirical laws in the case of a nonlogical concept, logical theorems in the case of a logical concept)" (Carnap 1950/1962: 7). However, what this criterion reasonably requires varies, arguably, depending on the context (Machery 2017). I suspect that the analysis I have proposed will be fruitful for two reasons. Firstly, it should allow us to draw insights about fake news from the general study of bullshit and, secondly, because it may permit us to gener-

31. An anonymous reviewer for this journal has suggested this strategy to me.

32. For recent book-long treatments of conceptual engineering that also address the normative criteria for the adequacy of an engineered concept, see Cappelen (2018) and Burgess, Cappelen, and Plunkett (in press). 
ate interesting hypotheses by relying on analogies between the phenomenon of fake news and other areas where bullshit is arguably a problem, for example, pseudoscience (Ladyman 2013). Fourthly and finally, an explicatum should, according to Carnap (1950/1962), be simple (though he intends this criterion only as a tie-breaker). This criterion, I think, speaks for itself in the present case. I have a hard time imagining a more straightforward analysis of fake news that is also sufficiently true to the other three criteria that Carnap proposed.

\section{Objection 2: The analysis is overexclusive.}

According to the second objection, the analysis is overexclusive, that is, it excludes cases which it should, intuitively, count as instances of fake news. One such example that critics have suggested to me is the following: Imagine a variation of PIZZAGATE. Call it PIZZAGATE*. Its details are the same as in the original case except that the publishers of the pizzagate conspiracy theory were not indifferent to the truth. Rather, they aimed at reporting a true story. However, their thinking followed what may be called a "crippled epistemology" (Sunstein and Vermeule 2009), which should, I take it, be interpreted as meaning that it relies on ways of reasoning that are significantly biased, fallacious, and irrational. ${ }^{33}$ Now, it seems that PIZZAGATE* is still a case of fake news. However, the bullshit condition appears not to be fulfilled because the publishers are not indifferent to the truth. This, in turn, suggests that my analysis of fake news is overexclusive.

The objection is important, I believe, because it shows that we need to tweak the bullshit conditions, $\mathrm{B}_{1}$ and $\mathrm{B} 2$. Ladyman (2013), who discusses the analogy between bullshit and pseudoscience, has developed an approach for doing this. As he notes, this analogy is prima vista problematic because "we usually assume that bullshitters know what they are doing," while "pseudoscientists are apparently genuinely seeking truth" (Ladyman 2013: 52). Ladyman answers this concern by pointing out that "one can bullshit unwittingly" and that "pseudoscience is often akin to that" (2013: 52). As he goes on to explain, "Just because one's first-order self-representations are that one is sincerely seeking the truth," one might, "in a deeper sense," "not care about it because one does not heed to the evidence" (Ladyman 2013: 52). On Ladyman's interpretation, then, truth-

33. Here I depart from the meaning of "crippled epistemology" that Sunstein and Vermeule (2009) intend. To them, a person has a crippled epistemology if "they know very few things, and what they know is wrong" (Sunstein and Vermeule 2009: 10). I believe that this interpretation is problematic for at least two reasons. Firstly, it is not even coherent since one cannot know things that are wrong. Secondly, we should, I believe, distinguish between a rational or irrational epistemology, as the case may be, and the deliverances of that epistemology, i.e., the beliefs the person following it develops. Accordingly, it seems preferable to me to interpret the term "crippled epistemology" as referring to a way of reasoning which is significantly biased, fallacious, and irrational. 
indifference $\left(\mathrm{B}_{1}\right)$ and the intention to deceive $\left(\mathrm{B}_{2}\right)$ are still the essential core of bullshit. However, the attitude of indifference need not be a conscious one. Rather, it can be located at a deeper level of the agent's psychology. Furthermore, the idea of deception is extended such that it also covers self-deception. ${ }^{34}$ Ladyman's modified, broad understanding of Frankfurtian bullshit can, hence, help us to accommodate cases like PIZZAGATE* which may, intuitively, be viewed as cases of fake news.

Now consider another variation of PIZZAGATE-call it PIZZAGATE**. Again, let us stipulate that all details are the same as in PIZZAGATE, except that the publishers of the story had a different motive. Suppose they knew that the story was untrue but published it anyway because they wanted to spread a lie. Intuitively, it may be argued, PIZZAGATE** also strikes us as a case of fake news. However, it does not seem to be a case of Frankfurtian bullshit but a case of lying.

At first glance, this objection can easily be countered because lying and bullshit are not exclusive categories. As Frankfurt explains, to bullshit is to make assertions "without paying attention to anything except what it suits one to say" (Frankfurt 2005: 60). A bullshitter may happen to know that a given assertion is false but choose not to pay attention to that fact since he is indifferent to the truth. In that case, he is not only a bullshitter. On the standard definition of lying, he is also a liar because he asserts something he knows to be false. Accordingly, PIZZAGATE**, it seems, can be construed as a case of Frankfurtian bullshit, too.

Note, however, that this is not the only possible interpretation. Instead, we may stipulate that the publisher does pay attention to things other than what it suits him to say. Suppose the only thing he cares about is to express a falsehood. In St. Augustine's words, he lies "from the sheer joy of lying" (Augustine 2002: 108). 35 On this interpretation, PIZZAGATE ${ }^{* *}$ still seems to involve an instance of fake news. However, since the publisher is not indifferent to the truth, there is no Frankfurtian bullshit. Rather, this is a case of what may be called "pure lying." Hence, PIZZAGATE** cannot be construed as involving an instance of Frankfurtian bullshit. Accordingly, I have to make a concession here. I have to make a distinction between two types of fake news, viz. the bullshit type (e.g., PIZZAGATE and PIZZAGATE*) and the pure lying type (e.g., PIZZAGATE**). Furthermore, I have to restrict the analysis I have proposed to the first type.

That said, I do not believe the concession makes a practical difference because the pure lying type of fake news does not seem to play any role in practice. This gets clear once we consider the motivations for spreading fake news.

34. For reasons of space, I shall not discuss the notion of self-deception here. See DeweeseBoyd (2017), for an instructive discussion.

35. According to St. Augustin, there are eight types of lies. PIZZAGATE** involves the fourth type where the liar does not tell the lie for instrumental reasons but for its own sake. 
Generally, there is either an ideological or a pecuniary motive (Allcott \& Gentzkow 2017). That is, publishers of fake news either seek to convince us of a particular political viewpoint, or they try to make money through advertisements. To accomplish these goals, they will say anything - whether true or false. There are, as far as I can see, practically no empirical exceptions. ${ }^{36}$ Accordingly, I suspect that the pure lying type of fake news does not occur in practice and that my analysis covers all real cases. I, therefore, submit that we should, for all practical purposes, understand fake news as a version of Frankfurtian bullshit, construed suitably broadly (following Ladyman 2013), which is asserted in the form of a news publication.

\section{Conclusion}

In this paper, I investigated the concept of fake news and proposed to analyse it as Frankfurtian bullshit asserted in the form of a news publication. In Section 1, I began with four cases that a satisfactory analysis should categorize correctly. After that, in Section 2, I considered some factors that might explain the difference between fake news and related phenomena. In Section 3, I proposed an analysis which I clarified in Section 4 and defended against two forms of objections in Section 5. One counter-example, however, prompted me to concede that my analysis only applies to the bullshit type of fake news and not to the pure lying type. As I explained, however, the latter type does not seem to occur in the real world such that my analysis should cover all practical cases of fake news.

If correct, my analysis will, I hope, help us to think more clearly about fake news when we investigate the phenomenon further. The most important and interesting question is, I believe, a practical one: What, if anything, should we do about fake news? Is it a problem sui generis, or is it, instead, a symptom of an underlying problem? At first glance, the answers to these questions may seem self-evident. We know, for example, that fake stories in favour of Donald Trump out-numbered the fake stories in support of Hillary Clinton by a substantial margin (Silverman 2016a). It is natural to suggest, therefore, that Trump's win was at least partly caused by fake stories favouring him. More generally, it seems reasonable to suppose that fake news stories can have a substantial impact on election outcomes. However, there is a different explanation based on well-established

36. One possible exception is the case of Paul Horner - an infamous fake news publisher. He claimed in one of his stories that a protester at a Trump rally admitted to having received 3,500\$. When asked for his motive, he replied that he "wanted to make fun of that insane belief" (Dewey 2016). Though this case might, at first glance, look more like a case of pure lying, it is not. Horner, after all, did not lie purely for lying's sake but in order to mock the gullibility of Trump supporters. In addition to that, however, he made a fair amount of money through ad revenues. 
findings in political psychology which suggests that voter preferences can explain the success of fake news stories. Trump supporters, it may be argued, were susceptible to fake stories because they confirmed their beliefs. On that account, the fundamental problem is not that fake news affected the election results but that voters will believe anything so long as it meshes with their political outlook. In that case, fake news is merely a symptom of a larger problem, viz. voters' tendency to look for information that confirms their prior beliefs (Lodge \& Taber 2013).37 I suspect that the causality goes both ways and that the proliferation of fake news, rather than being merely the effect of underlying psychological dispositions, can generate ethically relevant problems of its own..$^{38}$ Of course, I am unable to make a case for this hypothesis here. It is clear that more research needs to be done to gauge how large an effect fake news really has, how significant a problem it really poses, and what, if any, we should do about it.

\section{Acknowledgements}

I am indebted to Sven Bernecker, Dieter Birnbacher, Christine Bratu, David Coady, Nadja El-Kassar, Judith Fässler, Axel Gelfert, Thomas Grundmann, Joshua Habgood-Coote, Philipp Hübl, Christoph Jäger, Romy Jaster, Thomas Kaczmarek, Georgios Karageorgoudis, David Lanius, Julian Nida-Rümelin, Alexander Reutlinger, Regina Rini, Matthias Uhl, Sarah Wright, and the participants of the Fake Knowledge conference and GAP conference (both at Cologne, 2018) from whom I have received helpful comments and suggestions on a previous version of this paper. I would also like to thank two anonymous reviewers of this journal for their constructive criticisms of my argument as well as Robert Mason for suggesting corrections of the manuscript.

\section{References}

Adl-Tabatabai, Sean (2016, October 31). FBI Insider: Clinton Emails Linked to Political Pedophile Sex Ring. Your News Wire. Retrieved from https://yournewswire.com/fbiclinton-email-pedophile-ring

Allcott, Hunt, and Matthew Gentzkow (2017). Social Media and Fake News in the 2016 Election. Journal of Economic Perspectives, 31(2), 211-236. https://doi.org/10.1257/ jep.31.2.211

37. This well-known psychological phenomenon is called confirmation bias. It is the tendency of voters to "seek out confirmatory evidence and avoid what they suspect might be disconfirming evidence" (Lodge and Taber 2013: 156).

38. There is already some evidence that Trump's win was at least partly caused by antiClinton fake news (Gunther, Beck, \& Nisbet 2018). Research, however, still seems to be in an early stage.

Ergo vol. 5, no. $35 \cdot 2018$ 
Augustine (2002). Treatises on Various Subjects (The Fathers of the Church, Vol. 16). Catholic University of America Press.

Branham, Robert B. (2009). Satire. In Richard T. Eldridge (Ed.), The Oxford Handbook of Philosophy and Literature (139-161). Oxford University Press. https://doi.org/10.1093/ oxfordhb/9780195182637.003.0007

Burgess, Alexis, Herman Cappelen, and David Plunkett (Eds.) (in press). Conceptual Ethics and Conceptual Engineering. Oxford University Press.

Carnap, Rudolf (1950/1962). Logical Foundations of Probability. Routledge \& Kegan Paul.

Carson, Thomas L. (2009). Lying and Deception and Related Concepts. In Clancy Martin (Ed.), The Philosophy of Deception (153-187). Oxford University Press. https://doi. org/10.1093/acprof:0so/9780195327939.003.0010

Carson, Thomas L. (2010). Lying and Deception. Oxford University Press. https://doi. org/10.1093/acprof:0so/9780199577415.001.0001

Carson, Thomas L. (2016). Frankfurt and Cohen on Bullshit, Bullshiting, Deception, Lying, and Concern with the Truth of What One Says. Pragmatics $\mathcal{E}$ Cognition, 23(1), 53-67. https://doi.org/10.1075/pc.23.1.03car

Cohen, G. A. (2002). Deeper into Bullshit. In Sarah Buss and Lee Overton (Eds.), Contours of Agency - Essays on Themes from Harry Frankfurt (321-339). MIT Press.

Davis, Evan (2017). Post-truth: Why We Have Reached Peak Bullshit and What We Can Do about It. Little Brown.

Dentith, Matthew R. X. (2017). The Problems of Fake News. Public Reason, 8(1-2), 65-79.

Deweese-Boyd, Ian (2017). Self-Deception. In Edward N. Zalta (Ed.), The Stanford Encyclopedia of Philosophy (Fall 2017 Edition). Retrieved from https://stanford.io/2vpLacz

Dewey, Caitlin (2016, November 17). Facebook Fake-news Writer: 'I Think Donald Trump Is in the White House Because of Me'. The Washington Post. Retrieved from https://wapo.st/2vvPZn7

Emery, David (2017). Did President Trump Remove a MLK Bust from the Oval Office? Snopes. Retrieved from https://www.snopes.com/fact-check/mlk-bust-oval-office/

Evon, Dan (2017). George H.W. Bush Death Hoax. Snopes. Retrieved from https://www. snopes.com/fact-check/george-h-w-bush-obituary/

Frankfurt, Harry G. (2005). On Bullshit. Princeton University Press.

Gillin, Joshua (2017). PolitiFact's Guide to Fake News Websites and What They Peddle. PolitiFact. Retrieved from https://www.politifact.com/punditfact/article/2017/ apr/20/politifacts-guide-fake-news-websites-and-what-they/

Goodin, Robert E. and Kai Spiekermann (2018). An Epistemic Theory of Democracy. Oxford University Press. https://doi.org/10.1093/oso/9780198823452.001.0001

Grice, Paul (1989). Studies in the Way of Words. Harvard University Press.

Gunther, Richard, Paul A. Beck, and Erik C. Nisbet (2018). Fake News May Have Contributed to Trump's 2016 Victory. Unpublished manuscript. Retrieved from https:// www.documentcloud.org/documents/4429952-Fake-News-May-Have-Contributed-to-Trump-s-2016.html

Gupta, Anil (2015). Definitions. In Edward N. Zalta (Ed.), The Stanford Encyclopedia of Philosophy (Summer 2015 Edition). Retrieved from https://plato.stanford.edu/entries/ definitions/

Hunt, Elle (2016, December 17). What is Fake News? How to Spot It and What You Can Do to Stop It. The Guardian. Retrieved from https://www.theguardian.com/media/2016/dec/18/what-is-fake-news-pizzagate 
Hurlburt, Russell (2011). Investigating Pristine Inner Experience: Moments of Truth. Cambridge University Press. https://doi.org/10.1017/CBO9780511842627

Jacquette, Dale (2010). Journalism Ethics as Truth-Telling in the Public Interest. In Stuart Allen (Ed.), The Routledge Companion to News and Journalism (213-222). Routledge.

Jaster, Romy and David Lanius (in press). "What is Fake News?" Versus.

Keeley, Brian L. (1999). Of Conspiracy Theories. The Journal of Philosophy, 96(3), 109-126. https://doi.org/10.2307/2564659

Kessler, Glenn (2016, August 11). Too Good to Check: Sean Hannity's Tale of a Trump Rescue. The Washington Post. URL: http://wapo.st/2frZ8C

Kirby, Emma J. (2016, December 5). The City Getting Rich From Fake News. BBC. URL: http://bbc.in/2gweh4H

LaCapria, Kim (2016). Chuck E. Sleaze. Snopes. Retrieved from https://www.snopes.com/ pizzagate-conspiracy

LaCapria, Kim (2017). Snopes. Retrieved from https://www.snopes.com/fact-check/ creepy-clowns-halloween-night-purge

Ladyman, James (2013). Toward a Demarcation of Science from Pseudoscience. In Massimo Pigliucci and Maarten Boudry (Eds.), Philosophy of Pseudoscience: Reconsidering the Demarcation Problem (45-6o). University of Chicago Press. https://doi.org/10.7208/ chicago/9780226051826.003.0004

Lodge, Milton and Charles S. Taber (2013). The Rationalizing Voter. Cambridge University Press. https://doi.org/10.1017/CBO9781139032490

Machery, Édouard (2017). Philosophy Within Its Proper Bounds. Oxford University Press. https://doi.org/10.7312/columbia/9780231171953.003.0001

Mahon, James E. (2016) The Definition of Lying and Deception. In Edward N. Zalta (Ed.), The Stanford Encyclopedia of Philosophy (Winter 2016 Edition). Retrieved from https:// plato.stanford.edu/entries/lying-definition/

Mikkelson, David (2016). FBI Agent Suspected in Hillary Email Leaks Found Dead in Apparent Murder-Suicide. Snopes. Retrieved from https://www.snopes.com/factcheck/fbi-agent-murder-suicide/

Mulford, Carla (2008). Benjamin Franklin's Savage Eloquence: Hoaxes from the Press at Passy, 1782. Proceedings of the American Philosophical Society, 152(4), 490-530.

Pennycock, Gordon and David G. Rand (2017). Who Falls for Fake News? The Roles of Analytic Thinking, Motivated Reasoning, Political Ideology, and Bullshit Receptivity. Unpublished Manuscript. Social Science Research Network. Retrieved from https:// ssrn.com/abstract=3023545. https://doi.org/10.2139/ssrn.3023545

Rini, Regina (2017). Fake News and Partisan Epistemology. Kennedy Institute of Ethics Journal, 27(S2), 43-64. https://doi.org/10.1353/ken.2017.0025

Roese, Neal J. and Kathleen D. Vohs (2012). Hindsight Bias. Perspectives on Psychological Science, 7(5), 411-426. https://doi.org/10.1177/1745691612454303

Ryle, Gilbert (1949/2009). The Concept of Mind. Routledge. https://doi. org/10.4324/9780203875858

Schweikard, David P. and Hans B. Schmid (2013). Collective Intentionality. In Edward N. Zalta (Ed.), The Stanford Encyclopedia of Philosophy (Summer 2013 Edition). Retrieved from https://plato.stanford.edu/entries/collective-intentionality/

Shoichet, Catherine E., Ralph Ellis, and Jason Hanna (2016, July 23). Munich Shooting: 9 Victims, Gunman Dead, Police Say. CNN. Retrieved from https://www.cnn. com/2016/o7/22/europe/germany-munich-shooting/index.html

Silverman, Craig (2016a, November 16). This Analysis Shows How Fake Election News

$$
\text { Ergo } \cdot \text { vol. 5, no. } 35 \cdot 2018
$$


Stories Outperformed Real News on Facebook. Buzzfeed. Retrieved from https:// bzfd.it/2vDhnjq

Silverman, Craig (2016b, November 4). How the Bizarre Conspiracy Theory Behind "Pizzagate" Was Spread. Buzzfeed. Retrieved from https://bzfd.it/2v5HtbX

Singh, Simon (2006, March 25). A Groundbreaking Experiment . . . or a Sensationalised TV Stunt? The Guardian. Retrieved from https://www.theguardian.com/media/2006/ mar/25/science.broadcasting

Sunstein, Cass R. and Adrian Vermeule (2009). Conspiracy Theories: Causes and Cures. Journal of Political Philosophy, 17(2), 202-227. https://doi.org/10.1111/j.1467-9760.2008.00325.x

The Onion (2015, May 27). FIFA Frantically Announces 2015 Summer World Cup in United States. The Onion. Retrieved from https://sports.theonion.com/fifa-franticallyannounces-2015-summer-world-cup-in-uni-1819577826

Webber, Jonathan (2013). Liar! Analysis, 73(4), 651-659. https://doi.org/10.1093/analys/ anto81 